\title{
Comparative assessment of biologics in treatment of psoriasis: drug design and clinical effectiveness of ustekinumab
}

This article was published in the following Dove Press journal:

Drug Design, Development and Therapy

7 January 2011

Number of times this article has been viewed

\author{
Ignacio Garcia-Valladares \\ Raquel Cuchacovich \\ Luis R Espinoza \\ Section of Rheumatology, \\ Department of Internal Medicine, \\ LSU Health Sciences Center, \\ New Orleans, LA, USA
}

\begin{abstract}
The development of psoriasis and psoriatic arthritis is a multistep process that leads to chronic or recurrent inflammation. Recent studies have suggested the importance of T helper (TH) 1 and TH17 cells, accessory cells, and proinflammatory cytokines in the pathogenesis of the enthesis, synovium, and skin involvement in psoriasis in the presence of susceptibility genes that remain quiescent until triggered. Biologics, such as soluble CTLA-4 immunoglobulin, tumor necrosis factor (TNF) inhibitors, and ustekinumab, inhibit $\mathrm{T}$ cell activation which eventually leads to further stimulation of the interleukin 12, 17, and 23 axis, TNF- $\alpha$, and lymphotoxin- $\alpha$. Treatment with TNF- $\alpha$ blockers has been effective in refractory psoriasis and psoriatic arthritis, but there is still a subgroup of patients who do not respond to TNF inhibitors and, paradoxically, when treated, may develop TNF-induced psoriasis. Ustekinumab, because of its different mechanism of action at the level of the interleukin 12, 17, and 23 pathways, is an alternative treatment for this group of patients.
\end{abstract}

Keywords: psoriasis, psoriatic arthritis, biologics, ustekinumab, tumor necrosis factor inhibitors

\section{Introduction}

Psoriasis is a relatively common chronic inflammatory disease that affects around $3 \%$ of the general population, and is characterized by an exaggerated proliferation of keratinocytes secondary to an activated immune system. It has a predilection for Caucasians, with an estimated prevalence of $0.2 \%-3.0 \%$ in the general population. The incidence is highest at the age of 20-39 years in males and 40-59 years in females, with an equal male-to-female ratio. ${ }^{1}$

Psoriasis clinically manifests as raised, well defined erythematous plaques with irregular borders and silvery scales, affecting the upper and lower extremities equally, but with a predilection for the elbows, knees, scalp, and trunk. Psoriasis vulgaris or plaque psoriasis accounts for almost $90 \%$ of the dermatological presentation of the disease, but several other forms, including guttate, inverse, erythrodermal, pustular, and palmoplantar psoriasis may occur, as well as nail involvement. Psoriasis may have significant systemic involvement, which is underscored by the coexistence of various clinical disorders, including eye, cardiovascular, and intestinal problems, metabolic syndrome, and joint inflammation. It has a very high negative impact on quality of life, requires long-term treatment which usually has a high social and economic impact, and is also associated with a decreased life span.,3

Our understanding of the pathogenetic events leading to psoriasis has improved significantly in recent years. It is well established that an interplay of environmental, 
genetic, and immunological mechanisms is associated with development of the disease, and this has also led to the development of biologics resulting in significant advances in the management of severe or refractory forms of the disease. ${ }^{4-6}$ Three classes of biologics have been introduced, including $\mathrm{T}$ cell inhibitors, tumor necrosis factor (TNF)- $\alpha$ inhibitors, and most recently, ustekinumab, a biologic that targets the p40 subunit common to interleukins 12 and $23 .^{7}$

This review focuses on the effectiveness of biological therapy, particularly ustekinumab, in the treatment of psoriasis, and attempts to provide a comparative assessment of the different classes of biologics available for the treatment of psoriasis. In order to accomplish this, we have used the Psoriasis Area and Severity Index 75 (75\% response) score to compare the efficacy of current biologics. A recently published systematic review that analyzed all of the different clinical severity scores used for psoriasis concluded that the Psoriasis Area and Severity Index score has been the instrument used the most extensively and is now thoroughly validated. ${ }^{8}$

\section{Pathophysiology}

Genetic studies have clearly demonstrated that the incidence of psoriasis is higher among first- and second-degree relatives of patients with psoriasis than in the general population and, to date, nine chromosomal loci have been recognized as having a high predisposition for psoriasis. These are classified as susceptibility genes PSORS1 through to PSORS9, with PSORS1 being the most prevalent and accounting for almost $50 \%$ of heritability. ${ }^{9,10}$ PSORS2, PSORS3, and PSORS 4 are also associated with loci of susceptibility for metabolic syndrome, type 2 diabetes, familial hyperlipidemia, and cardiovascular disease. Genome-wide association studies have also identified several new genomic loci, and compelling evidence has shown an interaction between the HLA-C and ERAP 1 loci, implicating pathways that integrate epidermal barrier dysfunction with innate and adaptive immune dysregulation in psoriasis. ${ }^{11}$ CDKAL1 is also associated with type 2 diabetes genes with known function in cardiovascular risk, such as the ApoE4 isoform of apoprotein E, which is significantly more prevalent in patients with chronic plaque and guttate psoriasis than in controls.

A great body of evidence has accumulated in support of an important role for dysregulation of the immune system in the development of skin involvement in psoriasis, especially in the interplay between cells of the innate and adaptive immune systems and their inflammatory mediators in the skin epithelium and connective tissue (see Figure 1). It is still a matter of debate whether the epidermis, dermis, or a combination of both sites is primarily affected. One of the dysregulated immune mechanisms in psoriasis involves plasmacytoid dendritic cells and their high production of type I interferon (IFN)- $\alpha$ signal, which has been shown to be present in early skin lesions of psoriatic patients. ${ }^{12,13}$ Plasmacytoid dendritic cells are activated through complexes of antimicrobial peptides LL-37 cathelicidin and DNA in a toll-like receptor9-dependent manner, which may explain how immunological tolerance is disrupted in patients with psoriasis. ${ }^{14}$

More recently, increasing attention has been focused on keratinocytes, and substantial evidence suggests that these cells are a direct target for a specific set of cytokines, leading to regulation of their biological properties, such as secretion of cytokines, chemokines, and antimicrobial peptides, and their differentiation and migration capacities. ${ }^{15}$

Psoriasis is now considered the paradigm of an inflammatory disease involving the proinflammatory $\mathrm{T}$ helper (Th)17 subset. ${ }^{16,17}$ In vitro studies have characterized certain cytokines as being able to induce specific expression patterns related to the innate immune response, such as interleukin 1a, TNF- $\alpha$, interleukin $17 \mathrm{a}$, and oncostatin M, and may be able to induce skin inflammation reminiscent of psoriasis in animal models. ${ }^{18}$

Guilloteau et al identified an optimal and relevant cytokine combination able to synergize in vitro in order to generate an inflammatory keratinocyte model capturing some features of lesional psoriatic skin. ${ }^{19}$ In vitro and in vivo analyses were performed using normal and psoriatic skin samples, keratinocyte cell cultures, and murine models of skin inflammation. Following screening of 36 different cytokines, interleukins 1a, 1b, 6, 17a, 22, and 24, oncostatin $\mathrm{M}$, and TNF- $\alpha$ were identified as being able to modify the expression of at least five genes. Among these, interleukins 1a, 17a, and 22, as well as oncostatin M and TNF- $\alpha$, showed the strongest synergistic activity in the production of B defensin and CXCL8. Interleukin $17 \mathrm{a}$ and TNF- $\alpha$ were shown to be more crucial to the activity of this combination. It was concluded that the synergistic activity of several cytokines on keratinocytes is implicated in the pathogenesis of the disease..$^{20}$

Psoriatic skin and synovial fluid from patients with psoriatic arthritis are rich in various cytokines, including interleukins 6 , 17, and 23, as well as ROR $\gamma t$ (necessary for the induction of interleukin $1 \mathrm{R} 1$ and $23 \mathrm{R}$ receptor expression), which eventually mediates the activation of nuclear factor $\mathrm{\kappa B}$ and Stat signaling for further Th17 differentiation and lineage commitment. ${ }^{21}$ The pathogenetic role of Th17 cells is further supported by the increased concentrations of the $\mathrm{p} 40$ subunit of interleukins 


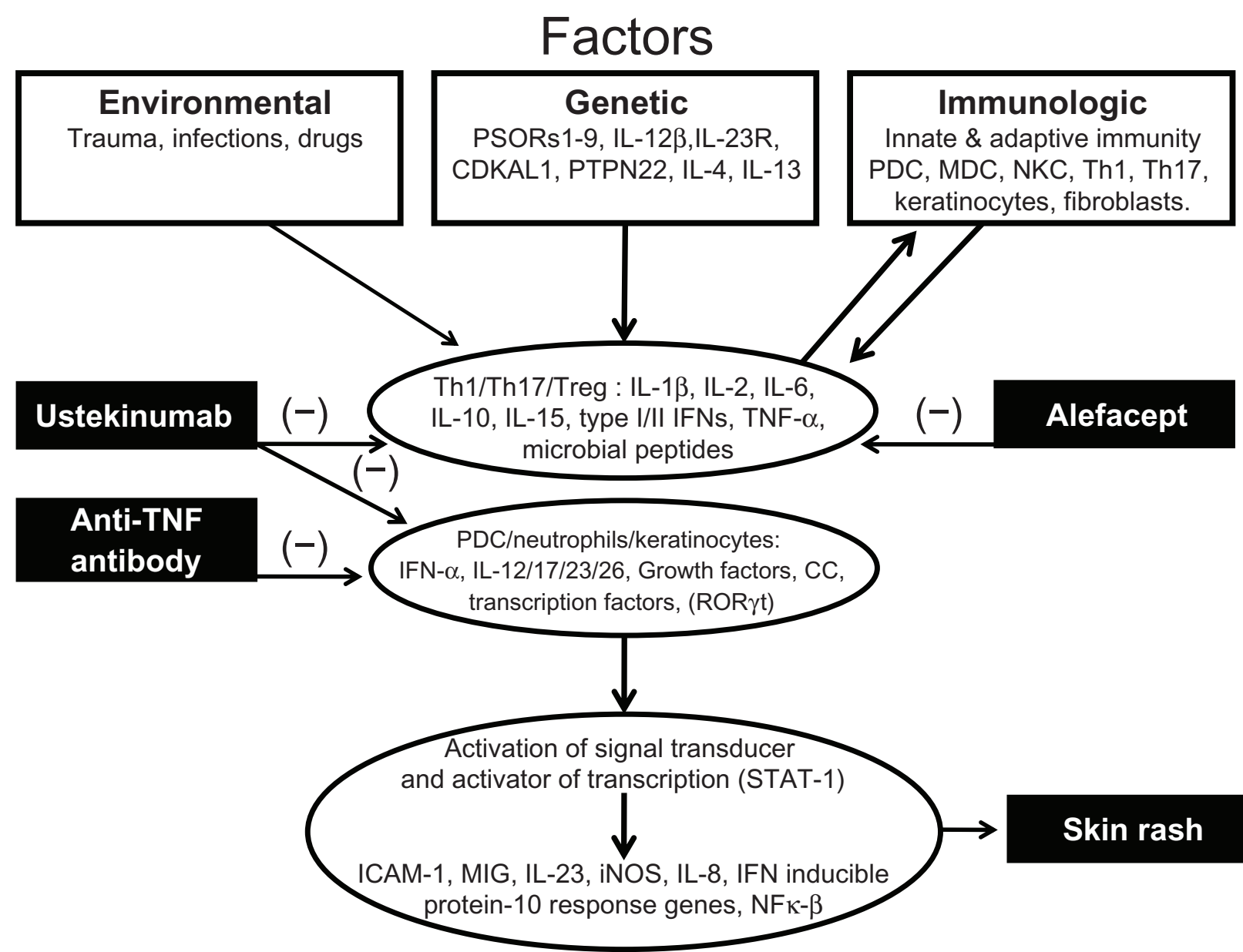

Figure I Pathophysiology of psoriasis.

Abbreviations: PDC, plasmacytoid dendritic cells; MDC, myeloid dendritic cells; NKC, natural killer cells; ThI and ThI7, Type I and I7 helper T cells; Treg, regulatory T cells; IL, interleukin; IFN, interferon; TNF, tumor necrosis factor; CC, chemokines.

12,23 , and 17 that are overexpressed in the affected skin and psoriatic joints. $^{22,23}$ Many of the molecules involved in the immunological response are targeted by the newer biologics, including ustekinumab, and are the focus of this discussion.

\section{Treatment}

Conventional treatment includes topical agents, phototherapy, and/or systemic immunosuppressive agents. However, therapy for moderate to severe or refractory psoriasis has been revolutionized with the introduction of biologics in the past 7-10 years. ${ }^{24-27}$ The first US Food and Drug Administration (FDA) biologic approved for plaque psoriasis was alefacept in January 2003, and this was followed by six other agents, ie, efalizumab in October 2003, infliximab in September 2006, etanercept and adalimumab, and most recently, ustekinumab, approved in September $2009^{28}$ (Table 1).

The overall efficacy and safety profile of biological therapy is well established. However, long-term safety data are lacking, and caution with its use should be taken into consideration due to an increase risk of opportunistic infections, worsening of heart failure, development of neurologic disease, and malignancy. Efalizumab was voluntarily withdrawn from the market in June 2009, due to a potential risk of patients developing progressive multifocal leukoencephalopathy. $^{29}$

\section{Alefacept}

Alefacept was the first biologic introduced for the treatment of moderate to severe psoriasis. Alefacept is a human fusion protein of the CD2-binding region of leukocyte functionassociated antigen-3 and the $\mathrm{CH} 2$ and $\mathrm{CH} 3$ domains of immunoglobulin $\mathrm{G}$, and acts to inhibit $\mathrm{T}$ cell activation and induces apoptosis of memory $\mathrm{T}$ cells. ${ }^{25}$

The first relevant clinical trials used alefacept as monotherapy for chronic plaque psoriasis. Ellis et al conducted a multicenter, randomized, controlled Phase II trial of 229 
Table I Biologic agents: general characteristics

\begin{tabular}{|c|c|c|c|c|}
\hline \multirow[t]{2}{*}{ Biologic } & \multirow[t]{2}{*}{ Structure } & \multirow[t]{2}{*}{ Dosage } & \multirow{2}{*}{$\frac{\text { Efficacy }}{\text { PASI } 75}$} & \multirow{2}{*}{$\begin{array}{l}\text { Major } \\
\text { Safety issues }\end{array}$} \\
\hline & & & & \\
\hline Alefacept & Human LFA-3 & 15 mg: qw for 12 weeks & week $14 \%-33 \%$ & Lymphopenia \\
\hline$\left(\right.$ Amevive $\left.{ }^{\circledR}\right)$ & Fusion protein & repeat qw for 12 weeks & week $24 \%-60 \%$ (PASI 50 ) & \\
\hline Infliximab & Chimeric monoclonal & $5 \mathrm{mg} / \mathrm{kg}: 0,2,6, \mathrm{q} 8 \mathrm{w}$ & week $10 \%-80 \%$ & Infusion reactions \\
\hline (Remicade ${ }^{\circledR}$ ) & anti-TNF- $\alpha$ antibody & & week $24 \%-82 \%$ & Opportunistic infections \\
\hline Etanercept & Human p75 TNF-receptor & 50 mg: biw for 12 weeks & week I $2 \%-49 \%$ & Injection site reactions \\
\hline$\left(\right.$ Enbrel $\left.^{\circledR}\right)$ & Fc fusion protein & 50 mg: qw & week $24 \%-54 \%$ & Opportunistic Infections \\
\hline Adalimumab & Human monoclonal & $80 \mathrm{mg}:$ loading dose & week $16 \%-7 \mid \%$ & Injection site reactions \\
\hline$\left(\right.$ Humira $\left.^{\circledR}\right)$ & anti-TNF- $\alpha$ antibody & 40 mg: qow & week $24 \%-70 \%$ & Opportunistic infections \\
\hline Ustekinumab & Human monoclonal & $90 \mathrm{mg}: 0,4, \mathrm{q} \mid 2 \mathrm{w}$ & week $12 \%-66 \%$ & Opportunistic infections \\
\hline$\left(\right.$ Stelara $\left.^{\circledR}\right)$ & anti-p40 antibody & & week $40 \%-90 \%$ & \\
\hline
\end{tabular}

Abbreviations: biw, twice weekly; LFA, lymphocyte function associated antigen; PASI, psoriasis area and severity index; TNF, tumor necrosis factor.

patients who received one of three doses of intravenous alefacept $(0.025 \mathrm{mg}, 0.075 \mathrm{mg}$, or $0.150 \mathrm{mg} / \mathrm{kg})$ or placebo for 12 weeks, with a 12-week follow-up. The PASI 75 score improved by $38 \%$ to $53 \%$ in the alefacept group compared with $21 \%$ in the placebo group. Long-term follow-up in these groups of patients showed a sustained response for up to 10 months, some even up to 18 months before retreatment. $^{25,30}$

Phase III clinical trials have shown similar results regarding alefacept. Menter et al determined the efficacy of multiple courses of alefacept in patients who failed to achieve a $>50 \%$ reduction in PASI after their first course of treatment. They demonstrated that multiple-course therapy in these patients had almost a double increase in achieving PASI 75 scores, from $29 \%$ to $54 \%$ in patients receiving one course compared with five courses of treatment. ${ }^{31}$

Two other randomized, double-blind, placebo-controlled Phase III studies were performed to evaluate the efficacy and tolerability of alefacept in patients with chronic plaque psoriasis. Alefacept administered intravenously or intramuscularly was shown to be effective and well tolerated for chronic plaque psoriasis. ${ }^{32,33}$ Additionally, a multicenter, observational Phase IV Canadian study of psoriasis patients treated with alefacept, known as AWARE (Amevive ${ }^{\circledR}$ Wisdom Acquired from Real-world Evidence), was performed. The main goals of AWARE were to develop a shared, real-time, national clinical database to support best practice and optimize the care of patients receiving alefacept and to gain an understanding of how alefacept is used in Canadian clinical practice. All patients in the AWARE patient population were receiving one or more treatments for psoriasis prior to or at baseline, and the majority continued to receive concomitant treatment at the time of study enrollment. It was concluded that alefacept was commonly added to other antipsoriatic therapies in Canada, and may allow for dosage reduction or discontinuation of concomitant systemic agents or phototherapy. ${ }^{34,35}$

Several studies have shown that alefacept is the least commonly prescribed biological therapy for psoriasis, but is a safe and well tolerated drug, with fatigue and arthralgia as the main adverse reactions, and an incidence of around $20 \%{ }^{36,37}$

However, as with most new emerging therapeutic agents, cost has become an important factor regarding treatment of patients. In a recent study, Beyer and Wolverton analyzed the total cost of systemic psoriasis therapies, concluding that the total cost of alefacept administered as two 12-week courses was around US $\$ 30,000$ compared with an approximate cost of US $\$ 1000$ for methotrexate. ${ }^{38}$

\section{TNF inhibitors}

Anti-TNF- $\alpha$ agents were the next class of biologics to be approved by the FDA for the treatment of moderate to severe chronic plaque psoriasis, with infliximab being the first approved. Its potential beneficial use for the treatment of psoriasis was recognized following the observation of elevated levels of anti-TNF in both skin and serum, which have a positive correlation with disease activity scores and a significant reduction after successful treatment. ${ }^{39}$

\section{Infliximab}

Infliximab is a chimeric monoclonal antibody formed from murine and human DNA sequences by binding a mouse variable region and a human IgG1- $\alpha$ constant region. It has the ability to bind to both forms of TNF, and transmembrane and soluble receptors, thus achieving complete blockade of TNF- $\alpha .{ }^{27,28}$ At a dosage of $5 \mathrm{mg} / \mathrm{kg}$ over $2-3$ hours at baseline, at weeks 2 and 6 , and every eight weeks thereafter, infliximab showed an average $80 \%$ response on PASI scores. In the pivotal clinical trials, $80 \%$ of patients achieved a PASI 
75 score at week 10 and $60 \%$ achieved a sustained response at week 50 , with a $90 \%$ improvement in the Dermatology Life Quality Index. ${ }^{40,41}$

One of the most remarkable effects of infliximab is the rapid response seen, noted even during the first two weeks of treatment. ${ }^{42}$ Nearly half rheumatoid arthritis patients treated with infliximab develop anti-infliximab antibodies within the first year of treatment, and the concomitant use of other immunosuppressive agents, especially methotrexate, could prevent new antibody formation. ${ }^{43,44}$

\section{Etanercept}

Etanercept is a recombinant human TNF- $\alpha$ receptor (p75) protein fused to the $\mathrm{Fc}$ portion of $\operatorname{IgG1}$, that binds not only the TNF-soluble and transmembrane portions, but also lymphotoxin- $\alpha$. Similar to other TNF inhibitors, etanercept is also approved for the treatment of other autoimmune conditions, such as spondyloarthropathies and rheumatoid arthritis. ${ }^{28}$ Etanercept is administered for psoriasis at a dose of $50 \mathrm{mg}$ subcutaneously twice a week for the first 12 weeks and thereafter once a week. Efficacy has been reported in many pivotal trials, with an average of $50 \%$ of patients achieving a PASI 75 score at week 12 compared with $4 \%$ in the placebo groups, and $60 \%$ of patients achieving PASI 75 at week 24 after continuous treatment. ${ }^{4-47}$ The presence of nonneutralizing antietanercept antibodies occurs in a small proportion of psoriasis patients and is not related to a decreased response to therapy. Neutralizing antibodies have not been described to date. ${ }^{48}$

\section{Adalimumab}

Adalimumab is the first fully humanized monoclonal antibody against TNF- $\alpha$. Like infliximab and etanercept, adalimumab inhibits both and TNF-soluble and transmembrane particles, and also the two surface receptor ligands, p75 and p55. Adalimumab is administered as a subcutaneous injection with a usual dose for psoriasis patients of $80 \mathrm{mg}$ in the first week, $40 \mathrm{mg}$ in the second week, and $40 \mathrm{mg}$ every two weeks thereafter in a continuous fashion. In the pivotal study of adalimumab for psoriasis, the clinical response observed was $70 \%$ in patients achieving PASI 75 scores at week 15 compared with $7 \%$ in patients on placebo. ${ }^{49,50}$ Development of antiadalimumab antibodies may occur in up to $20 \%$ of patients with rheumatoid arthritis, and may influence response to treatment. ${ }^{51}$

\section{Ustekinumab}

Ustekinumab is the latest biologic approved by the FDA for the treatment of moderate to severe plaque psoriasis. It is a human monoclonal antibody generated from transgenic mice by genetic engineering techniques. The main target of this biologic is the p40 subunit shared by two cytokines, interleukin 12 and 23, thereby preventing its interaction with the receptor and thus blocking subsequent signaling, differentiation, and cytokine production. ${ }^{52}$ Both cytokines are mainly produced by activated dendritic cells. Interleukin 12 mainly activates Th1 IFN- $\gamma$, TNF- $\alpha$, and cells producing interleukin 2 , whereas interleukin 23 has a main role in the development of Th17 and interleukin 22, and cells producing TNF- $\alpha .^{53}$

When the drug was designed, the intention was to test it in patients with ulcerative colitis, rheumatoid arthritis, psoriasis, psoriatic arthritis, and multiple sclerosis, because experimental mouse model analyses demonstrated blockade of interleukins 12 and 23, with subsequent prevention of arthritis and colitis. ${ }^{54}$

The most important clinical trials of ustekinumab for psoriasis are PHOENIX-1 and PHOENIX-2. Both are largescale, placebo-controlled Phase III trials designed to evaluate the efficacy and safety of the drug in patients with moderate to severe plaque psoriasis. . $^{55,56}$

The primary outcome in both studies was the proportion of patients achieving $\geq 75 \%$ improvement in PASI 75 scores at week 12 compared with baseline. The secondary outcomes included the Physician Global Assessment score of minimal or cleared psoriasis at week 12, a change from baseline in the Dermatology Life Quality Index at week 12, and in the randomized withdrawal phase, time to loss of PASI 75 response in the group receiving maintenance ustekinumab compared with the group withdrawn from the drug at week 40 . According to the inclusion criteria, patients had to be aged over 18 years, with a diagnosis of plaque psoriasis for at least six months, be candidates for phototherapy or systemic treatment, have more than $10 \%$ of body surface area involvement, and a PASI 75 score $\geq 12$. Exclusion criteria were mostly the same for other studies of biologics, ie, no symptoms of active tuberculosis, no recent serious infections, no known malignancy, and no recent treatment with biologic or topical agents.

In PHOENIX 1 and PHOENIX 2, 766 and 1230 patients with similar baseline characteristics were randomized, respectively, with almost two-thirds having been previously treated with phototherapy and one-half having been treated previously with conventional systemic treatments and/or biologics $^{55,56}$ (Table 2).

In PHOENIX 1, patients were randomized to receive ustekinumab $45 \mathrm{mg}$ or $90 \mathrm{mg}$, or placebo, at weeks 0 and 4 and then every 12 weeks thereafter. At week 12, patients in the placebo group were rerandomized to receive ustekinumab 
Table 2 Ustekinumab: Phase III clinical trials

\begin{tabular}{|c|c|c|c|c|c|}
\hline \multicolumn{3}{|l|}{ Phoenix I } & \multicolumn{3}{|l|}{ Primary endpoint } \\
\hline \multirow[t]{2}{*}{$\mathbf{N}$} & \multirow[t]{2}{*}{ Dosing } & \multirow[t]{2}{*}{ Week } & \multirow{2}{*}{$\frac{\text { PASI } 75 \text { response }}{\text { Week } 12}$} & \multicolumn{2}{|l|}{ Maximum efficacy } \\
\hline & & & & Week 24 & Week 28 \\
\hline 255 & $45 \mathrm{mg}$ & $0,4, q \mid 2 w$ & $67 \%$ & $76 \%$ & $71 \%$ \\
\hline 256 & $90 \mathrm{mg}$ & $0,4, q \mid 2 w$ & $66 \%$ & $85 \%$ & $78 \%$ \\
\hline \multirow[t]{3}{*}{255} & Placebo & & $3 \%$ & & \\
\hline & Placebo randomized & $\mathrm{n}=123$ & $45 \mathrm{mg}$ & Week 12, I6, q12w & $66 \%$ \\
\hline & & $\mathrm{n}=119$ & $90 \mathrm{mg}$ & Week I2, I6, qI2w & $85 \%$ \\
\hline Phoenix II & & & Primary endpoint & & \\
\hline \multirow[t]{2}{*}{$\mathbf{N}$} & Dosing & Week & PASI 75 response & Maximum efficacy & \\
\hline & & & Week I2 & Week 20 & Week 28 \\
\hline 411 & $90 \mathrm{mg}$ & $0,4, q \mid 2 w$ & $76 \%$ & $84 \%$ & $75 \%$ \\
\hline \multirow[t]{3}{*}{410} & Placebo & & $4 \%$ & & \\
\hline & Placebo randomized & $\mathrm{n}=193$ & $45 \mathrm{mg}$ & Week I2, I6, q12w & $70 \%$ \\
\hline & & $\mathrm{n}=194$ & $90 \mathrm{mg}$ & Week I2, I6, q12w & $79 \%$ \\
\hline
\end{tabular}

Notes: Phoenix I was designed in a three-way group I:I:I (ustekinumab 45, 90- and placebo with treatment at week 0 , 4, and every I2 weeks) with primary endpoint evaluating PASI 75 response at week 12. At that point placebo group was randomized into two groups (ustekinumab 45 and 90 mg with treatment at week I2, 16, and every 12 weeks). Therefore primary endpoint for the placebo randomized groups was at week 28 . At week 28 in all three groups nonresponders (PASI $<50)$ were discontinued from study, partial responders (PASI 50 to $<75$ ) began dosing every 8 weeks and PASI responders $(>75)$ continued every 12 weeks. At week 40 patients from the responders groups were re-randomized to either placebo or continue every 12 weeks and patients from the placebo group who were randomized to treatment returned to placebo and at loss of therapeutic effect were started back on ustekinumab with the last dose they were receiving. At that point nonresponders or partial responders were given ustekinumab every 8 weeks until week 76 end of study. Phoenix II was designed in the same way as Phoenix I but the only difference is that at week 28 partial responders were assigned to receive ustekinumab every 8 weeks and the study ended at week 52 , the same nonresponders were discontinued from study.

$45 \mathrm{mg}$ or $90 \mathrm{mg}$, with a subsequent dose at week 16 and every 12 weeks thereafter. At week 28, all partial responders (defined as PASI score 50-75) were switched to dosing every eight weeks and all nonresponders (defined as PASI score $<50$ ) had their therapy discontinued, but continued to be followed up. At week 40, all partial responders were switched to dosing every eight weeks, and responders (defined as PASI $>75$ ) were allocated to treatment continuation or treatment interruption. The PHOENIX 2 study was identical to PHOENIX 1, and all patients in both studies were to be followed up for five years.

In both trials, treatment with ustekinumab induced a rapid response rate, with a higher proportion of patients achieving PASI 50 from baseline by week 2 and PASI 75 by week 4 , compared with placebo.

Approximately $70 \%$ of the patients achieved the primary endpoint of PASI 75 at week 12 compared with $3 \%$ for the placebo group in both trials at the $45 \mathrm{mg}$ dose and an almost $80 \%$ response rate with the $90 \mathrm{mg}$ dose at week 12 . The highest response rate was achieved at week 24 , with a $76 \%$ response in the $45 \mathrm{mg}$ group and an $85 \%$ response in the $90 \mathrm{mg}$ group. At week 28 , more than $90 \%$ of patients were classified as partial responders and $50 \%$ of patients achieved a PASI 90 response rate, and efficacy was maintained until week 40 with dosing every 12 weeks.

Regarding safety and tolerability, there were no significant adverse events at both doses ( $45 \mathrm{mg}$ versus $90 \mathrm{mg}$ ) compared with placebo in either trial, and no anaphylactic reactions or serum sickness was observed. Furthermore, rates of infections were similar in both groups, with upper respiratory tract infections being the most common adverse events in approximately $13 \%$ in each group.

The only head-to-head comparison of biological therapy in patients with psoriasis was the ACCEPT (Efficacy and Safety of Ustekinumab Compared to Etanercept in the Treatment of Subjects with Moderate to Severe Plaque Psoriasis) trial, which was a comparison of etanercept and ustekinumab in 900 patients. In the etanercept group, patients received $50 \mathrm{mg}$ twice a week for 12 weeks, while two groups of patients received ustekinumab $45 \mathrm{mg}$ or $90 \mathrm{mg}$ at weeks 0 and $4 .{ }^{57}$

The results showed a PASI 75 response of $68 \%$ and $74 \%$ for both groups of patients who received ustekinumab, compared with a $57 \%$ response in the etanercept group at week 12, which achieved statistical significance at the levels of $P=0.01$ and $P<0.001$, respectively. The trial showed significant improvement in the Physician Global Assessment in patients who received ustekinumab compared with those on etanercept. Patients who were unresponsive to etanercept were switched to ustekinumab, with almost a $50 \%$ response rate within the first 12 weeks.

This head-to-head comparison clearly showed a significant superiority of ustekinumab over etanercept for the treatment of patients with moderate to severe psoriasis. The clinical and cost effectiveness of ustekinumab in relation to other biologics is uncertain. The provisional National 
Institute for Health and Clinical Excellence guidance issued as a result of the single technology appraisal process states that ustekinumab is recommended as a treatment option for adults with plaque psoriasis, but a number of criteria need to be met. ${ }^{58}$

The potential for infectious, malignant, metabolic, cardiovascular, and paradoxical complications should always be considered, and further studies are needed to assess the role of ustekinumab in the treatment of other musculoskeletal and extra-articular clinical conditions and comorbidities. ${ }^{24}$ However, it should be noted that ustekinumab has been shown to improve symptoms of anxiety, depression, and health-related quality of life significantly. ${ }^{59,60}$

Briakinumab (ABT-874) is another interleukin 12 and 23 inhibitor which is currently in Phase III clinical trials. Its efficacy for moderate to severe psoriasis appears to be comparable with that of ustekinumab. ${ }^{61}$ An abstract recently presented to the American Academy of Dermatology showed that 11 major adverse cardiovascular events were observed during the open-label extension study, in addition to seven from one run-in study. Using a composite of four cardiovascular risk factors, a retrospective analysis revealed that major adverse cardiovascular events occurred at a rate of $<0.3$ events $/ 100$ patient-years in patients with one or fewer risk factors compared with $>2.0$ events/100 patient-years in those with two or more risk factors. It was concluded that this interim analysis supports the need to monitor closely for adverse events of infection, malignancies, and cardiovascular risk factors that may contribute to major adverse cardiovascular events in patients receiving briakinumab for the treatment of moderate to severe psoriasis. ${ }^{61}$

Of interest, a series of reports has shown that ustekinumabtreated patients exhibit significant improvement in histological measures of psoriasis, with minimal impact on the systemic immune response. ${ }^{62}$ No changes in serum TNF- $\alpha$ concentrations were seen, or any significant variation in the percentages of cells expressing CD45RA, CD45RO, CD25, HLA-DR, and CXCR3 chemokine. In addition, no apparent effect on the magnitude of Th1/Th2 responses to external stimuli in peripheral blood mononuclear cells was observed following treatment with placebo or ustekinumab. ${ }^{62}$ Furthermore, administration of ustekinumab to both Cynomolgus monkeys and humans revealed that treatment does not significantly impair recall immune system functions, or have adverse effects on prenatal or postnatal development. ${ }^{63,64}$

In conclusion, accumulating evidence supports the efficacy and safety of ustekinumab for the treatment of moderate to severe psoriasis. There is some suggestion from head-to-head comparisons that ustekinumab may offer some advantage over TNF- $\alpha$ inhibitors. However, there is a need for larger and longer-term studies to assess the safety profile, cost-effectiveness, and advantages of anti-interleukin 12 and 23 activity in the modern era of biological therapy. ${ }^{65}$

\section{Disclosure}

The authors report no conflicts of interest in this work.

\section{References}

1. Nestle FO, Kaplan DH, Barker J. Psoriasis. N Engl J Med. 2009;361: 469-509.

2. Lebwolhl M. Psoriasis. Lancet. 2003;361:1197-1204.

3. Naldi L, Gambini D. The clinical spectrum of psoriasis. Clin Dermatol. 2007;25:510-518.

4. Lowes MA, Bowcock AM, Krueger JG. Pathogenesis and therapy of psoriasis. Nature. 2007;445:866-873.

5. Braun Falco O, Burg G. Inflammatory infiltrate in psoriasis vulgaris: A cytochemical study. Arch Klin Exp Dermatol. 1970;236: 297-314.

6. Schon MP, Boehncke WH. Psoriasis. N Engl J Med. 2005;352: 1899-1912.

7. Warren RB, Griffiths CE. The future of biological therapies. Semin Cutan Med Surg. 2010;29:63-66.

8. Puzenat E, Bronsard V, Prey S, et al. What are the best outcome measures for assessing plaque psoriasis severity? A systematic review of the literature. J Eur Acad Dermatol Venereol. 2010;24 Supp1 2:10-16.

9. Trembath RC, Clough RL, Rosbotham JL, et al. Identification of a major susceptibility locus on chromosome $6 \mathrm{p}$ and evidence for further disease loci revealed by a two stage genome-wide search in psoriasis. Hum Mol Genet. 1997;6:813-820.

10. Bowcock AM, Barker JN. Genetics of psoriasis: The potential impacts on new therapies. J Am Acad Dermatol. 2003;49 Suppl:S51-S56.

11. Strange A, Capon F, Spencer CC, et al. A genome-wide association study identifies new psoriasis susceptibility loci and an interaction between HLA-C and ERAP1. Nat Genet. 2010;42:985-990.

12. Funk J, Langeland T, Schrumpf E, Hanssen LE. Psoriasis induced by interferon-alpha. Br J Dermatol. 1991;125:463-465.

13. Nestle FO, Conrad C, Tun-Kyi A, et al. Plasmacytoid dendritic cells initiate psoriasis through interferon-alpha production. J Exp Med. 2005; 202:135-143.

14. Lande R, Gregorio J, Facchinetti V, et al. Plasmacytoid dendritic cells sense self-DNA coupled with antimicrobial peptide. Nature. 2007;449:564-569.

15. Madonna S, Scarponi C, Sestito R, et al. The IFN-gamma-dependent suppressor of cytokine signaling 1 promoter activity is positively regulated by IFN regulatory factor-1 and $\mathrm{Sp} 1$ but repressed by growth factor independence-1b and Kruppel-like factor-4 and is dysregulated in psoriatic keratinocytes. J Immunol. 2010;185:2467-2481.

16. Wilson NJ, Boniface K, Chan JR, et al. Development, cytokine profile and function of human interleukin 17-producing helper T cells. Nat Immunol. 2007;8:950-957.

17. Steiman L. A brief history of TH17, the first major revision in the TH1/ TH2 hypothesis of T cell-mediated tissue damage. Nat Med. 2007;13: 139-145.

18. Ma HL, Liang S, Li J, et al. IL-22 is required for Th17 cell-mediated pathology in a mouse model of psoriasis-like skin inflammation. J Clin Invest. 2008;118:597-607.

19. Guilloteau K, Paris I, Pedretti N, et al. Skin inflammation induced by the synergistic action of IL-17A, IL-22, oncostatin M, IL-1 $\alpha$, and TNF- $\alpha$ recapitulates some features of psoriasis. J Immunol. 2010;184: 5263-5270. 
20. Garcia-Valladares I, Espinoza LR. Psoriasis pathophysiology. Immunotherapy. 2010;2:444-445.

21. Fitch E, Harper E, Skorcheva I, et al. Pathophysiology of psoriasis: Recent advances on IL-23 and TH17 cytokines. Curr Rheumatol Rep. 2007;9:461-467.

22. Piskin G, Sylva-Steenland RMR, Bos JD, Teunissen MBM. In vitro and in situ expression of IL-23 by keratinocytes in healthy skin and psoriasis lesions: Enhanced expression in psoriatic skin. J Immunol. 2006;176:1908-1915.

23. Cuchacovich R, Espinoza LR. Ustekinumab for psoriatic arthritis. Lancet. 2009;373:605-606.

24. Menter A, Gottlieb A, Feldman SR, et al. Guidelines of care for the management of psoriasis and psoriatic arthritis: Section 1. Overview of psoriasis and guidelines of care for the treatment of psoriasis with biologics. J Am Acad Dermatol. 2008;58:826-850.

25. Ellis CN, Krueger GG. Treatment of chronic plaque psoriasis by selective targeting of memory effector T lymphocytes. N Engl J Med. 2001; 34:248-255.

26. Papp KA, Carey W. Psoriasis care: New and emerging pharmacologic trends. J Cutan Med Surg. 2010;14:119-129.

27. Weger W. Current status and new developments in the treatment of psoriasis and psoriatic arthritis with biological agents. Br J Pharmacol. 2010;160:810-820.

28. Nelson AL, Dhimolea E, Reichert JM. Development trends for human monoclonal antibody. Nat Rev Drug Discov. 2010;9:767-774.

29. Menter A. The status of biologic therapies in the treatment of moderate to severe psoriasis. Cutis. 2009;84(4 Suppl):14-24.

30. Dunn LK, Feldman SR. Alefacept treatment for chronic plaque psoriasis. Skin Therapy Lett. 2010;15:1-3.

31. Menter A, Cather JC, Baker D, et al. The efficacy of multiple courses of alefacept in patients with moderate to severe chronic plaque psoriasis. J Am Acad Dermatol. 2006;54:61-63.

32. Krueger GG, Papp KA, Stough DB, et al. A randomized, double-blind, placebo-controlled phase III study evaluating efficacy and tolerability of 2 courses of alefacept in patients with chronic plaque psoriasis. J Am Acad Dermatol. 2002;47:821-833.

33. Lebwohl M, Christophers E, Langley R, et al. An international, randomized, double-blind, placebo-controlled phase 3 trial of intramuscular alefacept in patients with chronic plaque psoriasis. Arch Dermatol. 2003;139:719-727.

34. Bissonnette R, Searles G, Landells I, et al. The AWARE study: Methodology and baseline characteristics. J Cutan Med Surg. 2009; 13 Suppl 3:S113-S121.

35. Searles G, Bissonnette R, Landells I, et al. Patterns of combination therapy with alefacept for the treatment of psoriasis in Canada in the AWARE study. J Cutan Med Surg. 2009;13 Suppl 3:S131-S138.

36. Perlmutter A, Cather J, Franks B, et al. Alefacept revisited: Our 3-year clinical experience in 200 patients with chronic plaque psoriasis. J Am Acad Dermatol. 2008;58:116-124.

37. Chaarani J, Lebwohl M. Alefacept: Where it stands today. Expert Opin Drug Metab Toxicol. 2010;6:355-361.

38. Beyer V, Wolverton SE. Recent trends in systemic psoriasis treatment costs. Arch Dermatol. 2010;146:46-54.

39. Prinz J, Braun-Falco O, Meurer M, et al. Chimeric CD4 monoclonal antibody in treatment of generalized pustular psoriasis. Lancet. 1991; 338:320-321.

40. Menter A, Feldman SR, Weinstein GD, et al. A randomized comparison of continous vs intermittent infliximab maintenance regimens over 1 year in the treatment of moderate-to-severe plaque psoriasis. J Am Acad Dermatol. 2007;56:1-15.

41. Reich K, Nestle FO, Papp K, et al. Infliximab induction and maintenance therapy for moderate-to-severe psoriasis: A phase III, multicenter, double-blind trial. Lancet. 2005;366:1367-1374.

42. Oh CJ, Das KM, Gottlieb AB. Treatment with anti-tumor necrosis factor alpha (TNF-alpha) monoclonal antibody dramatically decreases the clinical activity of psoriasis lesions. J Am Acad Dermatol. 2000;42: $829-830$.
43. Wolbink GJ, Vis M, Lems W, et al. Development of anti-infliximab antibodies and relationship to clinical response in patients with rheumatoid arthritis. Arthritis Rheum. 2006;54:711-715.

44. Bendtzen K, Geborek P, Svenson M, et al. Individualized monitoring of drug availability and immunogenicity in rheumatoid arthritis patients treated with the tumor necrosis factor alpha inhibitor infliximab. Arthritis Rheum. 2006;54:3782-3789.

45. Tyring S, Gottlieb A, Papp K, et al. Etanercept and clinical outcomes, fatigue, and depression in psoriasis: Double-blind placebo-controlled randomized phase III trial. Lancet. 2006;367:29-35.

46. Gottlieb A, Matheson RT, Lowe N, et al. A randomized trial of etanercept as monotherapy for psoriasis. Arch Dermatol. 2003;139:1627-1632.

47. Papp KA, Tyring S, Lahfa M, et al. A global phase III randomized controlled trial of etanercept in psoriasis: Safety, efficacy and effect of dose reduction. Br J Dermatol. 2005;152:1304-1312.

48. Romero-Mate A, Garcia-Donoso C, Cordova-Guijarro S. Efficacy and safety of etanercept in psoriasis/psoriatic arthritis: An updated review. Am J Clin Dermatol. 2007;8:143-155.

49. Menter A, Tyring SK, Gordon K, et al. Adalimumab therapy for moderate to severe psoriasis: A randomized, controlled phase III trial. J Am Acad Dermatol. 2008;58:106-115.

50. Gordon K. Efficacy and safety of adalimumab treatment in patients with moderate to severe psoriasis: A double-blind, randomized clinical trial. Psoriasis Forum. 2007;13:4-11.

51. Bartelds GM, Wijbrandts CA, Nurmohamed MT, et al. Anti-infliximab and anti-adalimumab antibodies in relation to response to adalimumab in infliximab switchers and anti-tumor necrosis factor naïve patients: A cohort study. Ann Rheum Dis. 2010;69:817-821.

52. van de Kerkhof PC. Novel biologic therapies in development targeting IL-12/IL-23. J Eur Acad Dermatol Venereol. 2010;Suppl 6:5-9.

53. Oppman B, Lesley R, Blom B, et al. Novel p19 protein engages IL-12p40 to form a cytokine, IL-23, with biological activities similar as well as distinct from IL-12. Immunity. 2000;13:715-725.

54. Butler DM, Malfait AM, Maini RN, et al. Anti-IL-12 and anti-TNF antibodies synergistically suppress the progression of murine collageninduced arthritis. Eur J Immunol. 1999;29:2205-2212.

55. Leonardi CL, Kimball AB, Papp KA, et al. Efficacy and safety of ustekinumab, a human interleukin-12/23 monoclonal antibody in patients with psoriasis: 76-week results from a randomized, double-blind, placebocontrolled trial (PHOENIX 1). Lancet. 2008;371:1665-1674.

56. Papp KA, Langley RG, Lebwohl M, et al. Efficacy and safety of ustekinumab, a human interleukin-12/23 monoclonal antibody, in patients with psoriasis: 52 -week results from a randomized, doubleblind, placebo-controlled trial (PHOENIX 2). Lancet. 2008;371: $1675-1684$

57. Griffiths EM, Strober BE, van de Kerkhof P, et al. Comparison of ustekinumab and etanercept for moderate-to-severe psoriasis. $N$ Engl J Med. 2010;362:118-128.

58. Gospodarevskaya E, Picot J, Cooper K, Loveman E, Takeda A. Ustekinumab for the treatment of moderate to severe psoriasis. Health Technol Assess. 2009;13 Suppl 3:61-66.

59. Langley RG, Feldman SR, Han C, et al. Ustekinumab significantly improves symptoms of anxiety, depression, and skin-related quality of life in patients with moderate-to severe psoriasis: Results from a randomized, double-blind, placebo-controlled phase II trial. J Am Acad Dermatol. 2010;63:457-465.

60. Lebwohl M, Papp K, Han C, et al. Ustekinumab improves health-related quality of life in patients with moderate-to-severe psoriasis: Results from the PHOENIX 1 trial. Br J Dermatol. 2010;162:137-146.

61. Langley R, Papp K, Gottlieb A, et al. Long-term safety and efficacy of ABT-874 for the treatment of moderate to severe psoriasis - interim analysis from an open-label extension study. Available from: http:// www.dermatology.ca/conference/2010/2010Abstracts.pdf. Accessed 2010 Dec 2.

62. Reddy M, Torres G, McCormick T, et al. Positive treatment effects of ustekinumab in psoriasis: Analysis of lesional and systemic parameters. J Dermatol. 2010;37:413-425. 
63. Martin PL, Sachs C, Imai N, et al. Development in the Cynomolgus macaque following administration of ustekinumab, a human antiIL-12/23p40 monoclonal antibody, during pregnancy and lactation. Birth Defects Res B Dev Reprod Toxicol. 2010;89:351-363.

64. Brodmerkel C, Zhu Y, Jiao Q, et al. Effects of ustekinumab administration on primate/human antigen-recall and humoral immune response functions. J Drugs Dermatol. 2010;9:677-683.
65. Ionescu MA, Lipozencic J. Could anti IL12/23 therapy replace anti-TNF biologics? Acta Dermatovenerol Croat. 2009;17:166-169.

\section{Publish your work in this journal}

Drug Design, Development and Therapy is an international, peerreviewed open-access journal that spans the spectrum of drug design and development through to clinical applications. Clinical outcomes, patient safety, and programs for the development and effective, safe, and sustained use of medicines are a feature of the journal, which has also been accepted for indexing on PubMed Central. The manuscript management system is completely online and includes a very quick and fair peer-review system, which is all easy to use. Visit http://www.dovepress.com/testimonials.php to read real quotes from published authors.

Submit your manuscript here: http://www.dovepress.com/drug-design-development-and-therapy-journal 